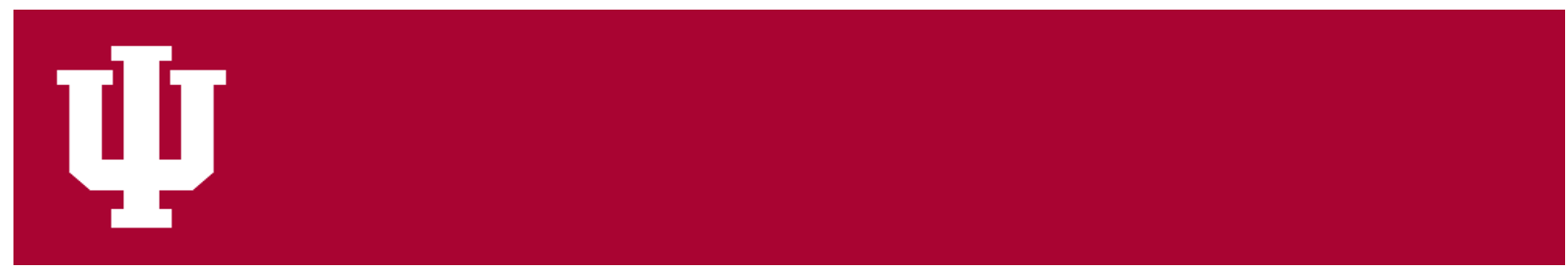

IUScholarWorks at Indiana University South Bend

\title{
Does National Culture Have Any Impact on E-Government Usage?
}

Merhi, Mohammad I.

To cite this article: Merhi, Mohammad I. "Does National Culture Have Any Impact on E-Government Usage?" International Journal of Technology Diffusion (IJTD), vol. 9, no. 3, 2018, pp. 29-45, DOI:10.4018/IJTD.2018070103

This document has been made available through IUScholarWorks repository, a service of the Indiana University Libraries. Copyrights on documents in IUScholarWorks are held by their respective rights holder(s). Contact iusw@indiana.edu for more information. 


\title{
Does National Culture Have Any Impact on E-Government Usage?
}

Mohammad I. Merhi, Indiana University South Bend, South Bend, USA

\begin{abstract}
The motivation of this article was the lack of empirical evidence regarding the relationship between culture and actual usage of ICTs/e-government. By using Hofstede's cultural framework, this article explains the influence of national culture on e-government usage across countries controlled by socioeconomic factors, specifically, GDP and literacy rate. Data was collected from reputable organizations such as World Bank databases and Hofstede's website. Ordinary least square and truncated regression are used to test the hypotheses presented in this article. Results indicate that nearly all Hofstede's cultural dimensions and e-government usage are significantly related. In particular, this article indicates that the usage of e-government is higher in nations that score low in power distance, uncertainty avoidance, individualism and masculinity.
\end{abstract}

\section{KEYWORDS}

Cross-Country Studies, Cross-Cultural Studies, E-Government Usage, Information and Communication Technologies, National Culture, Technology Usage

\section{INTRODUCTION}

In the last decade the diffusion rate of Information and Communication Technologies (ICTs), and specifically e-government, in public sector was remarkable. At the same time, the rates of e-government usage vary significantly across nations (UN, 2014). The existing e-government research has investigated many factors that affect e-government usage (e.g. Bertot, Jaeger, \& Grimes, 2010; Weerakkody, El-Haddadeh, Al-Sobhi, Shareef, \& Dwivedi, 2013). While it is true that each of these previous studies is significant in its way, it is noticed that the effect of national culture on e-government usage has yet to be thoroughly examined. The existing literature falls short when it comes to presenting a culturally-based interpretation of the differences in e-government usage rates across countries. The cultural factors are rooted in normative behavior of a society. Individuals generally act in a way that is aligned to the standards of behavior in a society (Deci \& Ryan, 2000). This study, and apart from the generally considered economic and individual factors, investigates the effect of national cultural factors on the usage of e-governments in 49 countries.

E-government is a cost-effective and convenient means (Kumar, Mukerji, Butt, \& Persaud 2007; Turban, King, Lee, Liang, \& Turban, 2015) that helps public organizations to store, process, transmit and report essential information easily and in a short time. It has been argued that ICTs in governments would improve service delivery (Ngafeeson \& Merhi, 2013; Zhao, Collier, \& Deng, 2014), efficiency and effectiveness (Choudrie, Grey, \& Nicholas, 2010; Merhi \& Koong, 2016; Nath \& Standing, 2010), interactivity (Leidner, 2010), decentralization, transparency (Merhi \& Koong, 2013) and reduce corruption (Shim \& Eom, 2008). Thus, it enables agencies and organizations to lower their operating costs, provide faster service to clients, and eliminate redundant IT development 
across departments and agencies (Goings, Young, \& Hendry, 2003). Consequently, e-government became a necessity and not a choice for any country wishing to enter the twenty-first century as a competitive nation (Yang, Harris, \& Whitfield, 2009).

Although it is true that e-government has many advantages that help both governments and citizens achieve efficiency and satisfaction, it is not clear whether citizens will use such services or not (Levy, Bagby, \& Trauth, 2013). Evidence shows that the usage rates of e-government in governments differ significantly across countries with similar economic situations (UN, 2014). One possible explanation for this is, may be the meaning attributed to technologies differs among people depending on their socio-cultural attitudes (Erumban \& de Jong, 2006; Steers, Meyer, \& SanchezRunde, 2008). Hofstede $(1984,2001)$ has shown that differences in values and attitudes influence the way people interact and make use of their environment. Thus, within a specific society, these socio-cultural values might manipulate the perception of the citizens in a certain way that influence the usage decisions. In fact, different cultures react differently to new products and technological innovations (Gong, Li, \& Stump, 2007) which made cultural differences to become an important issue in the evaluation of technologies (Al-Gahtani, Hubona, \& Wang, 2007).

This study is an extension to the culture-based research that has focused on information technology (IT) adoption and usage (Bagchi, Hart, \& Peterson, 2004; Erumban \& de Jong, 2006; Gong et al., 2007; Wallace, Reid, Clinciu, \& Kang, 2013) who found that a decision to adopt ICT is influenced by the social, cultural and perceived values of the individuals within a society. IS researchers (Almutairi, 2008; Hsu, Tien, Lin, \& Chang, 2015; Lee, Choi, Kim, \& Hong, 2007; Zakour, 2008) have identified cultural values as one of influential factors on technology usage and concluded that national culture influences and shapes the shared values of the people. In e-government literature, most of the research has focused on the adoption rather than actual usage. Adopting new technologies is not a hard issue, but making people use the technologies later on is a different and hard issue. The usage of technologies tends to be permanent because usage generally determines how much value users derive from the technologies over time. On the other hand, adoption tends to be temporarily because users might decide to give up after a period of time. Adopting the technology does not mean that users are certainly going to use it. Reports show that the usage rates of technologies are still quite low in many countries compared to the adoption rates (First Data, 2011). Thus, adoption alone is not necessarily the best measure of technology usage. Instead, actual usage generally determines how much value users derive from the technology and whether they are going to use it or not (Goldfarb \& Prince, 2008). This current study attempts to investigate whether national culture affects e-government usage or not.

By exploring how the national cultural dimensions affect users' beliefs and behaviors to use e-government, this study fills a gap in the literature. The research question addressed by this paper is: Can national culture influence the actual usage of e-government across different countries? The concept of culture adopted and used in this paper is based on Hofstede's framework. Besides contributing to the scholarly literature, this study should be of great interest to decision makers of governments who seek to increase the use of e-governments and ICTs in their countries. This study should also be of interest to decision makers of multinational organizations because they depend on the use of ICTs by people belonging to different cultures. The results reported in this study can also lead to development of new theories that may enrich both research and practice.

The remainder of this paper is organized as follows. Section 2 provides a brief background on e-government usage and national culture. Section 3 explains the research model and research hypotheses. Section 4 describes the methodology. Section 5 discusses the results. Section 6 notes the paper limitations and identifies opportunities for future research. Finally, section 7 concludes the paper by summarizing the paper implications and highlighting its contributions. 
15 more pages are available in the full version of this document, which may be purchased using the "Add to Cart" button on the product's webpage:

www.igi-global.com/article/does-national-culture-have-anyimpact-on-e-government-usage/204916?camid=4v1

This title is available in InfoSci-Technology Adoption, Ethics, and Human Computer Interaction eJournal Collection, InfoSci-Journals, InfoSci-Journal Disciplines Computer Science, Security, and Information Technology, InfoSciJournal Disciplines Business, Administration, and Management, InfoSci-Select. Recommend this product to your librarian:

www.igi-global.com/e-resources/libraryrecommendation/?id=153

\section{Related Content}

Mobile Commerce Use among UK Mobile Users Based on a Proposed Mobile Network Utilization Framework: An Experimental Approach - Part 2 Asem Moqbel, Mirella Yani-Di-Soriano and Shumaila Yousafzai (2010). International Journal of Technology Diffusion (pp. 1-33).

www.igi-global.com/article/mobile-commerce-use-among-

mobile/46154?camid=4v1a

Individual and Contextual Determinants of Citizens Use of Government Websites

Marc Fudge and Gregg Van Ryzin (2012). International Journal of Technology Diffusion (pp. 44-58).

www.igi-global.com/article/individual-contextual-determinants-citizensuse/68162?camid=4v1a 
Multi-Dimensional Factors Impacting on E-Government Adoption in Botswana, Mozambique, and Malawi

Kelvin Joseph Bwalya, Tanya Du Plessis and Chris Rensleigh (2013). Adoption of

Virtual Technologies for Business, Educational, and Governmental Advancements (pp. 58-71).

www.igi-global.com/chapter/multi-dimensional-factors-impacting-

government $/ 72398$ ?camid=4v1a

Economic Growth, Technical Progress and Labor Productivity: Knowledge Economics and New Forms of Technical Progress

Alain Herscovici (2011). International Journal of Innovation in the Digital Economy (pp. 35-47).

www.igi-global.com/article/economic-growth-technical-progress-

labor/51581?camid=4v1a 